\title{
KARAKTERISTIK IBU BERHUBUNGAN DENGAN PERSEPSI IBU TERHADAP BUKU KESEHATAN IBU DAN ANAK (KIA)
}

\author{
Vianty Mutya Sari ${ }^{1}$, Nurhasanah $^{2 *}$ \\ 1,2STIKes Muhammadiyah Cirebon \\ *Korespondensi email khansa_noer@yahoo.com
}

\section{ABSTRACT MOTHER'S CHARACTERISTICS RELATED TO MOTHER'S PERCEPTION OF MOTHER AND CHILD HEALTH BOOK (MCH)}

Background: In Indonesia, breast cancer is the second leading cause of death for women after cervical cancer. Based on data from the Cirebon City Health Office in 2015, the number of maternal deaths was 4/5400 live births, the number of infant deaths was 25/5455 live births, the number of under-five deaths was 8/5378 live births. The aspects of maternal and child health can be seen from several indicators of achievement, one of which is Infant Immunization, in 2015 out of 22 urban villages in the city of Cirebon there was only one sub-district that had not reached the target, namely in the Argasunya sub-district. While the coverage of health care delivery in Argasunya was $52.64 \%$ (from data on the coverage of health care workers, $108.37 \%$, only $55.73 \%$ gave birth at the health facility) and the highest birth attendance by traditional birth attendants in Cirebon was in the Argasunya village of $4.63 \%$.

The purpose of this study was to determine the relationship between characteristics and perceptions of pregnant women on the $\mathrm{MCH}$ Handbook

Methods: This study used a cross sectional design. The population of all pregnant women in Benda Kerep Village, Argasunya Village, Cirebon City. Sampling using total sampling. The data taken is primary data obtained through a questionnaire given to 23 pregnant women. Correlation test used is Chi-Square.

Research Results The majority of pregnant women had a poor perception of the $\mathrm{MCH}$ handbook (69.56\%). The majority of pregnant women have an age of 20-35 (87\%). The majority of education for pregnant women (completing SD) (78\%). The majority of gestational age is included in the second trimester, namely 14-27 weeks (48\%). The majority of pregnant women had a planned place of delivery at home (73.92\%). Conclusion Based on occupation, all pregnant women are not working (100\%). There is no relationship between the age of pregnant women and the mother's perception of the $\mathrm{MCH}$ handbook. There is no relationship between the education of pregnant women and the mother's perception of the $\mathrm{MCH}$ handbook. There is no relationship between the occupation of pregnant women and the mother's perception of the $\mathrm{MCH}$ handbook. There is no relationship between the planning of the place of delivery of pregnant women and the perceptions of mothers towards the MCH handbook.

Suggestions Future research is expected to be able to examine it more deeply by adding other components currently contained in the latest edition of the $\mathrm{MCH}$ book using the appropriate method.

Keywords: Characteristics, Perception, MCH Handbook

\section{ABSTRAK}

Latar Belakang : Di Indonesia, Kanker payudara menduduki peringkat kedua penyebab kematian wanita setelah kanker leher rahm. Berdasarkan data Dinas Kesehatan Kota Cirebon Tahun 2015, jumlah kematian Ibu 4/5400 kelahiran hidup, jumlah kematian bayi 25/5455 kelahiran hidup, jumlah kematian balita 8/5378 kelahiran hidup. Aspek kesehatan ibu dan anak dapat di lihat dari beberapa indikator pencapaian salahsatunya Imunisasi Bayi, pada tahun 2015 dari 22 kelurahan di kota Cirebon hanya ada satu kelurahan yang belum mencapai target yaitu di kelurahan Argasunya. Sedangkan cakupan persalinan naskes di Argasunya sebesar 52,64\% (dari data cakupan persalinan nakes $108,37 \%$ hanya $55,73 \%$ yang bersalin di Faskes) dan pertolongan persalinan oleh dukun tertinggi di kota cirebon adalah di kelurahan argasunya sebesar $4,63 \%$.

Tujuan dari penelitian ini adalah untuk mengetahui hubungan Karakteristik dengan persepsi lbu hamil terhadap Buku KIA 


\section{JKM (Jurnal Kebidanan Malahayati),Vol 7,No.4.Oktober 2021, \\ ISSN (Print) 2476-8944 ISSN (Online) 2579-762X, Hal 704-710}

Metode : Penelitian ini menggunakan desain cross sectional. Populasi seluruh ibu hamil di Desa Benda Kerep Kelurahan Argasunya Kota Cirebon. Pengambilan sampel dengan menggunakan Total sampling. Data yang diambil merupakan data primer yang didapat melalui wawancara kepada 23 ibu hamil dengan menggunakan kuesioner. Uji Korelasi yang digunakan adalah Chi-Square.

Hasil :Mayoritas ibu hamil memiliki persepsi yang kurang baik terhadap buku KIA (69,56 \%). Mayoritas Ibu hamil memiliki usia 20-35 (87\%). Mayoritas pendidikan ibu hamil (Tamat SD) (78\%). Mayoritas Usia kehamilan adalah termasuk trimester II yaitu 14-27 minggu (48\%). Mayoritas ibu hamil memiliki rencana tempat persalinan adalah di rumah $(73,92 \%)$.

Kesimpulan Berdasarkan pekerjaan seluruh ibu hamil tidak bekerja (100\%). Tidak ada hubungan antara usia ibu hamil dengan persepsi ibu terhdapa buku KIA. Tidak ada hubungan antara pendidikan ibu hamil dengan persepsi ibu terhdapa buku KIA. Tidak ada hubungan antara pekerjaan ibu hamil dengan persepsi ibu terhdapa buku KIA. Tidak ada hubungan antara rencana tempat bersalin ibu hamil dengan persepsi ibu terhadap buku KIA.

Saran Penelitian selanjutnya diharapkan dapat mengkaji lebih dalam dengan menambahkan komponenkomponen lain yang saat ini terdapat pada buku KIA edisi terbaru menggunakan metode yang sesuai.

Kata Kunci : Karakteristik, Persepsi, Buku KIA

\section{PENDAHULUAN}

Kematian pada ibu dapat terjadi selama masa kehamilan, pada saat bersalin serta masa nifas yang disebabkan oleh kurangnya pengetahuan untuk mengenali adanya tanda bahaya yang dialami seperti mual muntah yang berlebih, perdarahan, ketuban pecah dini, demam, bengkak pada kaki tangan bahkan wajah disertai tekanan darah tinggi dan gerakan janin yang berkurang. Pengetahuan terkait tanda bahaya pada masa kehamilan penting untuk diketahui oleh ibu hamil agar dapat secepat mungkin meminta bantuan atau pertolongan apabila menemui tandatanda bahaya tersebut (Napitupulu dkk, 2018).

Buku Kesehatan Ibu dan Anak (KIA) juga berisi informasi penting yang dibutuhkan oleh ibu dan keluarga yang harus disampaikan oleh petugas kesehatan melalui komunikasi informasi dan edukasi untuk meningkatkan pengetahuan dan perilaku kesehatan ibu hamil dan keluarga agar ibu dan keluarga mampu menjaga, memantau dan meningkatkan kesehatan ibu hamil dan janin serta ibu dan keluarga mengenali tanda bahaya sedini mungkin pada ibu hamil sehingga bisa dilakukan penatalaksanaan dengan cepat. Hal ini dapat mengurangi angka kejadian ibu hamil resiko tinggi dan mengurangi angka kematian ibu (Kemenkes, 2015).

Departemen kesehatan bersama Japan International Coorperation Agency (JICA) membuat buku KIA sejak tahun 1993 sampai saat ini terus dievaluasi dan dilakukan revisi secara berkala sesuai kebutuhan ibu dan anak, seiring dengan perkembangan zaman yakni berisi informasi kesehatan ibu hamil, bersalin, nifas, imunisasi, tumbuh kembang balita, penanganan pertama bayi sakit, perawatan anak dengan disabilitas dan cara melindungi anak dari kekerasan seksual (Kemenkes, 2015).

Kurangnya pengetahuan ibu tentang penggunaan buku Kesehatan Ibu dan anak (KIA) yakni masih dianggap hanya sebagai buku pencatatan kesehatan bagi petugas kesehatan menjadi kendala dalam pembentukan perilaku kesehatan ibu hamil tentang pentingya melakukan periksa kehamilan secara rutin, memahami tanda bahaya kehamilan secara dini, pentingya minum tablet Fe secara teratur, serta perawatan kesehatan sehari-hari (Depkes RI, 2005).

Program buku KIA saat ini merupakan salah satu program prioritas di Indonesia, sehingga Pemerintah menargetkan capaian pemanfaatan buku KIA pada tahun 2014 yaitu sebesar 85\% (Kemenkes RI, 2015). Menurut data Riskesdas tahun 2018, proporsi di Indonesia kepemilikan Buku KIA adalah 65,9 \%, 49,7\% memiliki dan dapat menunjukan, $16,2 \%$ memiliki dan tidak dapat menunjukan (Kemenkes, 2018).

Pemanfaatan buku KIA ini dipengaruhi oleh beberapa faktor. Berdasarkan teori yang dikembangkan oleh Lawrence Green (1991), menyebutkan bahwa beberapa faktor yang dapat mempengaruhi perilaku seseorang yaitu yang pertama faktor predisposisi (pengetahuan, sikap, kepercayaan, nilai-nilai dan budaya). Rendahnya pemanfaatan buku KIA masih terkendala oleh rendahnya pengetahuan dan sikap ibu tentang manfaat dari buku KIA dan sebagian ibu juga menganggap hal-hal yang berhubungan dengan buku KIA hanya sekedar buku catatan pemeriksaan (Puji, dkk, 2015). Kedua yaitu faktor pemungkin (lingkungan fisik, biaya, sarana atau fasilitas kesehatan). Keterjangkauan jarak, ketersediaan transportasi dan ketersediaan fasilitas kesehatan di 
lingkungan ibu memberikan pengaruh yang besar dalam memanfaatkan pelayanan kesehatan, salah satunya yaitu dalam menggunakan buku KIA (Mulia, 2005). Terakhir yaitu faktor pendorong atau penguat (sikap dan perilaku petugas kesehatan) (Notoatmodjo, 2010). Hasil Penelitian Hasanbasri dan Ernoviana (2006) di Kota Sawalunto menunjukkan bahwa $80 \%$ petugas kesehatan tidak memberikan penyuluhan kepada ibu sesuai dengan materi yang terdapat dalam buku KIA.

Berdasarkan fakta yang ada, maka peneliti tertarik untuk melakukan penelitian mengenai Hubungan Karakteristik dengan Persepsi lbu terhadap buku KIA pada Ibu Desa Benda Kerep Kelurahan Argasunya Kota Cirebon. Hal ini penting untuk diketahuiagar hasil penelitian yang didapat nantinya bisa memberikan informasi yang berguna bagi pihak puskesmas, sehingga pemanfaatan buku KIA dapat meningkat dan juga dapat dimanfaatkan dalam pengembangan bidang kesehatan ibu dan anak.

\section{METODE PENELITIAN}

Jenis penelitian ini adalah penelitian kuantitatif dengan menggunakan desain penelitian analitik observasional dengan rancangan studi cross-sectional. Populasi yang digunakan yaitu seluruh ibu hamil di Desa Benda Kerep Kelurahan Argasunya Kota Cirebon. Teknik pengambilan sampel yang digunakan adalah total sampling dimana sampel adalah keseluruhan populasi yang berjumlah 23 ibu hamil. Teknik pngumpulan data melalui wawancara menggunakan kuesioner yang telah baku untuk mengukur persepsi ibu terhadap buku KIA.

\section{HASIL DAN PEMBAHASAN}

Berdasasrkan table distribusi diatas, mayoritas ibu hamil memiliki persepsi yang kurang baik terhadap buku KIA yaitu sebesar 69,56 \%, mayoritas memiliki usia 20-35 sebesar $87 \%$, mayoritas sekolah (Tamat SD) sebesar 78 persen, mayoritas ibu hamil umur kehamilannya adalah termasuk trimester II yaitu 14-27 minggu sebanyak 10 orang (48\%), mayoritas ibu hamil memiliki rencana tempat persalinan adalah di rumah sebesar 17 orang atau $73,92 \%$ dan seluruh ibu hamil tidak bekerja 23 orang(100\%).
Tabel 1

Hasil Univariat

\begin{tabular}{l|cc}
\hline \multicolumn{1}{c}{ Kategori } & Frekuensi & Prosentase \\
\hline Persepsi & & \\
Baik & 7 & 30,43 \\
Kurang baik & 16 & 69,56 \\
Usia ibu & & \\
$<20$ & 1 & 4,31 \\
$20-35$ & 20 & 87 \\
$>35$ & 2 & 8,69 \\
$\begin{array}{l}\text { Pekerjaan ibu } \\
\text { Bekerja }\end{array}$ & 0 & 0 \\
Tidak bekerja & 23 & 100 \\
Pendidikan & & \\
Sekolah & 18 & 78 \\
Tidak sekolah & 5 & 22 \\
$\begin{array}{l}\text { Rencana tempat } \\
\text { persalinan }\end{array}$ & & \\
$\begin{array}{l}\text { Poned } \\
\text { Pmb }\end{array}$ & 3 & 13,04 \\
Dirumah & 3 & 13,04 \\
Usia kehamilan & 17 & 73,92 \\
Trimester 1 (1- & & \\
13mg) & & \\
Trimester 2 (14- & 6 & 26 \\
27mg) & 11 & 48 \\
Trimester 3 (28- & & \\
41mg) & 6 & 26 \\
\hline
\end{tabular}

Tabel 2.

Hubungan Usia Ibu dan Persepsi tentang buku KIA

\begin{tabular}{lcc}
\hline Persepsi Usia lbu & Baik & Kurang baik \\
\hline$<20$ & 1 & 0 \\
$20-35$ & 7 & 13 \\
$>35$ & 0 & 2 \\
\hline
\end{tabular}

Dari tabel 2, dapat diketahui bahwa dari 21 responden memiliki persepsi kurang baik terhadap buku KIA, paling banyak berusia 20-35 tahun. Setelah dilakukan uji statistic dengan menggunakan chi square diperoleh $x^{2}$ hitung sebesar 3,361 dan $x^{2}$ tabel dengan $\mathrm{df}=2$ dan $\alpha=0,05$ yaitu 5,991. Karena $x^{2}$ hitung $<x^{2}$ tabel maka Ha ditolak artinya tidak ada hubungan antara usia ibu hamil dengan persepsi ibu terhdapa buku KIA. 
Tabel 3.

Hubungan Pendidikan Ibu dengan Persepsi tentang Buku KIA

\begin{tabular}{lcc}
\hline Persepsi Pendidikan & Baik & Kurang baik \\
\hline Sekolah & 7 & 11 \\
Tidak sekolah & 1 & 4 \\
\hline
\end{tabular}

Dari tabel 3, dapat diketahui bahwa dari 23 responden memiliki persepsi kurang baik terhadap buku KIA, paling banyak berpendidikan SD. Setelah dilakukan uji statistic dengan menggunakan chl square diperoleh $\mathrm{x}^{2}$ hitung sebesar 0,611 dan $\mathrm{x}^{2}$ tabel dengan $\mathrm{df}=1$ dan $\alpha=0,05$ yaitu 3,841 . Karena $\mathrm{x}^{2}$ hitung $<\mathrm{x}^{2}$ tabel maka Ha ditolak artinya tidak ada hubungan antara pendidikan ibu hamil dengan persepsi ibu terhdapa buku KIA.

Tabel 4.

Hubungan Pekerjaan Ibu dengan Persepsi tentang buku KIA

\begin{tabular}{lcc}
\hline Persepsi Pekerjaan & Baik & Kurang baik \\
\hline Bekerja & 0 & 0 \\
Tidak bekerja & 8 & 15 \\
\hline
\end{tabular}

Dari tabel 4, dapat diketahui bahwa dari 23 responden memiliki persepsi kurang baik terhadap buku KIA, paling banyak tidak bekerja. Setelah dilakukan uji statistic dengan menggunakan chi square diperoleh $x^{2}$ hitung sebesar 0,211 dan $x^{2}$ tabel dengan $\mathrm{df}=1$ dan $\mathrm{a}=0,05$ yaitu 3,841. Karena $x^{2}$ hitung $<x^{2}$ tabel maka Ha ditolak artinya tidak ada hubungan antara pekerjaan ibu hamil dengan persepsi ibu terhdapa buku KIA.

Tabel 5.

Hubungan Rencana Tempat Bersalin dengan Persepsi tentang buku KIA

\begin{tabular}{lcc}
\hline $\begin{array}{l}\text { Persepsi Rencana } \\
\text { Tempat Bersalin }\end{array}$ & Baik & Kurang baik \\
\hline PONED & 1 & 2 \\
PMB & 2 & 1 \\
RUMAH & 5 & 12 \\
\hline
\end{tabular}

Dari tabel 5 , dapat diketahui bahwa dari 23 responden memiliki persepsi kurang baik terhadap buku KIA, paling banyak rencana tempat bersalin di rumah. Setelah dilakukan uji statistic dengan menggunakan chl square diperoleh $x^{2}$ hitung sebesar 1,96 dan $\mathrm{x}^{2}$ tabel dengan $\mathrm{df}=2$ dan $\alpha=0,05$ yaitu 5,991. Karena $x^{2}$ hitung $<x^{2}$ tabel maka Ha ditolak artinya tidak ada hubungan antara rencana tempat bersalin ibu hamil dengan persepsi ibu terhadap buku KIA.

Tabel 6.

Hubungan Umur kehamilan ibu dengan persepsi tentang buku KIA

\begin{tabular}{lcc}
\hline $\begin{array}{l}\text { Persepsi Umur } \\
\text { Kehamilan }\end{array}$ & Baik & Kurang baik \\
\hline trimester 1 (1-13mg) & 0 & 3 \\
trimester 2 (14-27mg) & 8 & 6 \\
trimester 3 (28-41mg) & 3 & 3 \\
\hline
\end{tabular}

Dari tabel 6, dapat diketahui bahwa dari 23 responden memiliki persepsi baik terhadap buku $\mathrm{KIA}$, paling banyak usia kehamilan ibu dalam trimester II. Setelah dilakukan uji statistic dengan menggunakan chl square diperoleh $x^{2}$ hitung sebesar 3,273 dan $x^{2}$ tabel dengan $d f=2$ dan $a=$ 0,05 yaitu 5,991 . Karena $x^{2}$ hitung $<x^{2}$ tabel maka $\mathrm{Ha}$ ditolak artinya tidak ada hubungan antara rencana usia kehamilan ibu dengan persepsi ibu terhdapa buku KIA.

\section{PEMBAHASAN}

Berdasarkan hasil distribusi mayoritas ibu hamil memiliki persepsi yang kurang baik terhadap buku KIA yaitu sebesar 69,56 \%.

Berdasarkan teori oleh Walgito (2017) persepsi adalah suatu proses diterimanya stimulus oleh individu melalui alat atau juga disebut proses sensoris. Stimulus tersbut akan diteruskan dan proses selanjutnya merupakan proses persepsi. Diantara Faktor yang mempengaruhinya adalah Usia (Nursalam, 2001) Semakin cukup usia, kematangan dan kekuatan seseorang akan lebih matang dalam berfikir dan bekerja. Pendidikan (Notoatmojo, 2017) Seseorang dengan pendidikan yang tinggi akan memberikan tanggapan yang lebih rasional. Pekerjaan (Notoatmojo, 2013) seseorang yang bekerja dapat memperoleh pengetahuan yang baik tentang sesuatu hal sehingga dapat mempersepsikan sesuatu dengan positif.

Berdasarkan analisis bivariat, ibu hamil mayoritas memiliki usia 20-35 sebesar $87 \%$. Dan Dari tabel 7, dapat diketahui bahwa dari 21 responden memiliki persepsi kurang baik terhadap buku KIA, paling banyak berusia 2035 tahun. Setelah dilakukan uji statistic dengan menggunakan chi square diperoleh $x^{2}$ hitung 
sebesar 3,361 dan $\mathrm{x}^{2}$ tabel dengan $\mathrm{df}=2$ dan $\alpha=0,05$ yaitu 5,991. Karena $x^{2}$ hitung $<x^{2}$ tabel maka Ha ditolak artinya tidak ada hubungan antara usia ibu hamil dengan persepsi ibu terhdapa buku KIA.

Dari hasil penelitan diatas tidak sesuai dengan teori yang menyatakan bahwa usia produktif (20-35 tahun) mempunyai pemikiran dan pemahaman yang baik terkait kesehatan reproduksinya, usia produktif akan memberikan keadaan fisik yang lebih siap dibandingkan dengan usia $<20$ tahun dan $>35$ tahun.

Hasil penelitian Hegiwara (2013) ibu dengan usia produktif lebih tertarik memanfaatkan buku KIA dan selalu membawa buku KIA sebagai media komunikasi dengan petugas kesehatan. Artinya seharusnya pada usia 20-35 persepsi ibu terhadap buku KIA baik, karena pada usia produktif tingkat kematangan dan kekuatan seseorang dlam berfikir dan bertindak akan lebih baik (Notoatmojo, 2007). Namun pada penelitian ini, pada ibu hamil dengan usia 20-35 tahun memiliki persepsi kurang baik, hal ini peneliti berasumsi bahwa, terdapat faktor lain yang dapat mempengaruhi adanya persepsi tersebut, misalnya pendidikan, kurangnya pengetahuan karena tidak bekerja, tingginya interaksi antara ibu hamil dan tenaga kesehatan, dan faktor lain yang belum termasuk dalam variabel penelitian.

Berdasarkan analisis bivariat, ibu hamil mayoritas sekolah (Tamat SD) sebesar 78 persen. Dan Dari tabel 8, dapat diketahui bahwa dari 23 responden memiliki persepsi kurang baik terhadap buku KIA, paling banyak berpendidikan SD. Setelah dilakukan uji statistic dengan menggunakan chl square diperoleh $x^{2}$ hitung sebesar 0,611 dan $x^{2}$ tabel dengan $\mathrm{df}=1$ dan $\alpha=0,05$ yaitu 3,841 . Karena $\mathrm{x}^{2}$ hitung $<\mathrm{x}^{2}$ tabel maka Ha ditolak artinya tidak ada hubungan antara pendidikan ibu hamil dengan persepsi ibu terhadap buku KIA.

Menurut Heru, 2005 dalam Sistiarini 2014, Pendidikan adalah proses belajar yang berarti didalam pendidikan terjadi proses pertumbuhan dan perkembangan menuju kedewasaan dan kematangan indivudu. Menurut Sukmadinata, 2003 dalam Sistiarini 2014, Pendidikan diperlukan untuk mendapatkan informasi yang menunjang kesehatan sehingga dapat meningkatkan kualitas hidup seseorang.

Buku KIA dengan desain sangat sederhana dan menarik dengan berbagai gambar sehingga mudah dipahami oleh ibu hamil dengan pendidikan yang rendah, hal ini diartikan bahwa buku KIA efektif sebagai media komunikasi antara ibu hamil dengan tenaga kesehatan. Pendapat ini sesuai dengan Nakamura (2010) dalam Sistiarini (2014) bahwa di Indonesia ibu hamil dengan pendidikan rendah lebih banyak tertarik memanfaatkan buku KIA dibandingkan dengan ibu hamil dengan pendidikan tinggi.

Berdasarkan hasil analisis bivariat, mayoritas ibu hamil umur kehamilannya adalah termasuk trimester II yaitu 14-27 minggu sebanyak 10 orang (48\%) dan dari tabel 6, dapat diketahui bahwa dari 23 responden memiliki persepsi baik terhadap buku KIA, paling banyak usia kehamilan ibu dalam trimester II. Setelah dilakukan uji statistic dengan menggunakan chl square diperoleh $x^{2}$ hitung sebesar 3,273 dan $x^{2}$ tabel dengan $d f=2$ dan $a=$ 0,05 yaitu 5,991 . Karena $x^{2}$ hitung $<x^{2}$ tabel maka Ha ditolak artinya tidak ada hubungan antara usia kehamilan ibu dengan persepsi ibu terhdapa buku KIA.Semakin besar umur kehamilan menjadikan ibu lebih banyak menggunakan buku KIA dikarenakan jumlah kunjungan pemeriksaan kehamilan yang bertambah hal ini sesuai anjuran Kemenkes (2020), Pelayanan antenatal (Antenatal Care/ANC) pada kehamilan normal minimal $6 x$ dengan rincian $2 x$ di Trimester 1, 1x di Trimester 2, dan 3x di Trimester 3. Minimal $2 x$ diperiksa oleh dokter saat kunjungan 1 di Trimester 1 dan saat kunjungan ke 5 di Trimester 3. Seiring juga dengan adanya ketidaknyamanan yang dirasakan ibu boleh melakukan kunjungan dan hal ini yang menjadikan ibu akan lebih sering menggunakan buku KIA. Penelitian yang dilakukan oleh Nzioki (2015) bahwa ibu yang memanfaatkan buku KIA cenderung mencari informasi terkait kesehatan ibu dan bayi seperti dalam hal akses pelayanan ANC, perawatan masa nifas, imunisasi bayi dan penggunaan KB setelah 6 bulan persalinan.

Berdasarkan analisis bivariat, bisa dilihat mayoritas ibu hamil memiliki rencana tempat persalinan adalah di rumah sebesar 17 orang atau $73,92 \%$. Dari 23 responden memiliki persepsi kurang baik terhadap buku KIA, paling banyak rencana tempat bersalin di rumah. Setelah dilakukan uji statistic dengan menggunakan chl square diperoleh $x^{2}$ hitung sebesar 1,96 dan $x^{2}$ tabel dengan $\mathrm{df}=2$ dan $\alpha=0,05$ yaitu 5,991 . Karena $x^{2}$ hitung $<x^{2}$ tabel maka Ha ditolak artinya tidak ada hubungan antara rencana tempat bersalin ibu hamil dengan persepsi ibu terhadap buku KIA.

Perencanaan persalinan merupakan suatu standar pelayanan kepada ibu hamil yang bertujuan untuk mengetahui bagaimana pemenuhan psikologis ibu bersalin dalam menentukan keyakinannya dan kenyamanan baginya. Salah satu perencanaan persalinan adalah menentukan tempat 


\section{JKM (Jurnal Kebidanan Malahayati),Vol 7,No.4.Oktober 2021, \\ ISSN (Print) 2476-8944 ISSN (Online) 2579-762X, Hal 704-710}

bersalin, pemilihan tempat bersalin yang tepat dapat memberikan dampak pada keadaan ibu bersalin.

Beberapa hasil penelitian menyebutkan bahwa pendidikan yang tinggi dapat menyebabkan pengetahuan tentang kesehatan sehingga ibu hamil dapat merencanakan untuk memilih tempat persalinan di fasilitas pelayanan kesehatan.

Penelitian sebelumnya dilakukan Oki,dkk (2015), yaitu ibu yang memiliki buku KIA memiliki kemungkinan 2,39 kali lebih besar untuk melakukan persalinan ditolong oleh tenaga kesehatan dibandingkan dengan ibu yang tidak memiliki buku KIA.

Seperti juga penelitian yang dilakukan oleh Dewi (2015) bahwa terdapat hubungan antara pendidikan dan pemilihan persalinan. Dari hasil penelitian menunjukkan tingkat pendidikan ibu hamil di desa benda sebagian besar tidak tamat sekolah, hal ini yang diasumsikan menjadi faktor pemilihan persalinan di rumah.

Berdasarkan analisis bivariat dari 23 responden memiliki persepsi kurang baik terhadap buku KIA, paling banyak tidak bekerja. Setelah dilakukan uji statistic dengan menggunakan chi square diperoleh $x^{2}$ hitung sebesar 0,211 dan $x^{2}$ tabel dengan $d f=1$ dan $\alpha=0,05$ yaitu 3,841 . Karena $x^{2}$ hitung $<x^{2}$ tabel maka Ha ditolak artinya tidak ada hubungan antara pekerjaan ibu hamil dengan persepsi ibu terhdapa buku KIA.

Pekerjaan dapat diartikan sebagai gambaran pendapatan ekonomi suatu keluarga. Sesuai dengan teori persepsi bahwa pekerjaan dapat mempengaruhi seseorang dalam mendapatkan pengatahuan kesehatan sehingga dapat berdampak pada pemikiran yang positif.

Dalam penelitian ini seluruh ibu hamil mempunyai status tidak bekerja yang dapat diasumsikan sebagai kurangnya wawasan yang didapatkan dari aspek eksternal sehingga memberikan persepsi yang kurang baik terhadap buku KIA.

\section{SIMPULAN}

Tidak ada hubungan antara usia ibu hamil dengan persepsi ibu terhdapa buku KIA.Tidak ada hubungan antara pendidikan ibu hamil dengan persepsi ibu terhdapa buku KIA.Tidak ada hubungan antara pekerjaan ibu hamil dengan persepsi ibu terhdapa buku KIA.Tidak ada hubungan antara rencana tempat bersalin ibu hamil dengan persepsi ibu terhadap buku KIA.

\section{SARAN}

Penelitian selanjutnya diharapkan dapat mengkaji lebih dalam dengan menambahkan komponen-komponen lain yang saat ini terdapat pada buku KIA edisi terbaru menggunakan metode yang sesuai.

\section{DAFTAR PUSTAKA}

Depkes RI. (2005). Pedoman Pelayanan Antenatal. Departemen Kesehatan Republik Indonesia, Jakarta

Dewi MAritalia, 2015 : Hubungan Pendidikan ibu hamil terhadap Pemilihan Tempat Bersalin Di Wilayah Kerja Puskesmas Peusangan Kabupaten Bireuen. Jurnal Lentera Vol.15 No.14.

Ernoviana dan Hasanbasri M. (2006). Pemanfaatan Buku Kesehatan lbu dan Anak di Dinas Kesehatan Kota Sawahlunto. Yogyakarta.

Hagiwara, 2013. Is The Maternal and Child Health (MCH) Handbook Effective in Impriving Health - Related Behavior, Evidance From Palestina. Jornal of Public Policy Vol.34,1,31-34.

Kementerian Kesehatan RI. (2015). Petunjuk Teknis Penggunaan Buku Kesehatan Ibu Dan Anak. JICA: Jakarta

Kemenkes. 2018. Hasil Utama Riskesdas 2018. Badan Penelitian dan Pengembangan Kemsnkes RI

Mulia, R. (2005). Kesehatan Lingkungan. Edisi Pertama. Yogyakarta: Graha IImu

Napitupulu, dkk. (2018). Gambaran Pemanfaatan Buku KIA dan Pengetahuan lbu Hamil Mengenai Tanda Bahaya Kehamilan. Jurnal Kesehatan Vokasional. Vo.3 No. 1 Mei 2018

Nzioki, Japhet., Onyango, Rosebella., Ombaka, James. 2015. Socio demographic Factors Influencing Maternal and Child Mental Helat Service Utilization in Mwingi: A rural SemiArid District in Kenya. American Journal of Public Healt Reseach Vol. 3 No. 1, 21-30

Notoadmodjo. 2003. Metodologi Penelitian Kesehatan. Jakarta: Rineka Cipta.

Notoadmodjo. 2007.Pendidikan Dan Perilaku Kesehatan. Jakarta: PT Renika Cipta.

Nursalam \& Pariani. 2001. Pendekatan Praktik Metodologi Penelitian Keperawatan. Jakarta: Cv. Agung Setio.

Osaki K, Kosen S, Indriasih E, Pritasari K, Hattori T. Factors affecting the utilisation of maternal, newborn, and child health services in Indonesia: The role of the Maternal and 
Child Health Handbook. Public Health. 2015;129(5):582-6.

Puji Rahayu, Yayu dkk. (2015). Hubungan Pengetahuan dan Sikap lbu Hamil Tentang Tanda Bahaya Kehamilan Terhadap Pemanfaatan Buku KIA di UPT. Puskesmas Martapura. STIKES Sari Mulia Banjarmasin dan Poltekes Kemenkes Banjarbaru. Jurnal, Vol 13 No. 15, Juli 2015.

Sistiarni. (2014). Fungsi Pemanfaatan Buku Kesehatan Ibu dan Anak pada Ibu. Jurnal Kesehatan Masyarakat Nasional, Vol 8 No 8. Walgito, Bimo. (2010). Pengantar Psikologi Umum, Yogyakarta : CV Andi Offset, h.99 